\title{
PROGRAMA DE EXTENSÃO TEIA/UFV: FORMAC̣ÃO UNIVERSITÁRIA PARA UMA ECOLOGIA DE SABERES
}

\author{
Marcelo Loures dos Santos* \\ Willer Araújo Barbosa** \\ Manuelli Kölln***
}

RESUMO: A presente pesquisa analisou as contribuições do programa extensionista TEIA/UFV na formação de seus bolsistas, tendo como referência a proposta de Boaventura de Sousa Santos para a universidade do século XXI. Esse autor analisa a necessidade de se enfrentar o tradicional distanciamento entre a universidade e a sociedade, fortalecendo os pressupostos da Ecologia de Saberes. Foram realizadas entrevistas sobre as principais concepções compartilhadas por bolsistas quanto à sua participação e formação no TEIA e às quatro áreas de ação propostas para a construção dessa universidade: acesso universitário; extensão universitária; pesquisa-ação; e ecologia de saberes. Conclui-se que o Programa TEIA vem contribuindo para uma reforma democrática da universidade e das relações de desigualdade inerentes a ela na formação de seus integrantes, sendo essa formação percebida pelos bolsistas como um diferencial transformador, preparando-os para agir e refletir criticamente diante dos problemas sociais com os quais estão envolvidos.

Palavras-chave: Extensão Universitária; Ecologia de Saberes; Educação Intercultural.

\footnotetext{
* Doutor em Psicologia pela Pontifícia Universidade Católilca de Campinas (PUC-CAMPINAS); Professor do Programa de Pósgraduação em Educação no Departamento de Educação na Universidade Federal de Viçosa (UFV). E-mail: santos@ufv.br

* * Doutor em Educação pela Universidade Federal de Santa Catarina (UFSC); Professor da Universidade Federal de Viçosa (UFV). E-mail: willerab@hotmail.com

*** Mestanda em Educação pela Universidade Federal de Viçosa (UFV). E-mail: manuellikolln@ufv.br
} 
TEIA/UFV EXTENSION PROGRAM: UNIVERSITY EDUCATION FOR KNOWLEDGE ECOLOGY

ABSTRACT: This research sought to examine the contributions of the TEIA/UFV Extension Program to its scholars' formation process, taking as reference Boaventura de Sousa Santos' proposal to the $21^{\text {st }}$ century University. Boaventura examines the development of a posture to counter to the traditional gap between the University and society, strengthening the assumptions of Knowledge Ecology. Interviews were held on key concepts shared by scholars as to their involvement and training in the TEIA, and on the four action areas pointed to the construction of this University: University Access; University Extension; Action Research and Ecology of Knowledge. It is concluded that the TEIA Program has contributed to a democratic reform of the University and inequality relations intrinsic to it in its members' formation. Such training has being perceived by students as a differential transformer, preparing them to act and reflect critically on the social problems with which they are involved.

Keywords: University extension; Knowledge Ecology; Intercultural Education.

\section{Apresentação}

O paradigma da modernidade e seu modelo de desenvolvimento capitalista têm apresentado em seu bojo diversas contradições, representadas predominantemente pela crise da ciência moderna e da sociedade global como um todo. Esse modelo tem historicamente desvalorizado os conhecimentos, uniformizado culturas e homogeneizado modos de pensar e agir que não estejam de acordo com seu ideário. Invisibiliza, assim, diversos grupos sociais do uso e legitimação de seus saberes interculturais diante da sociedade.

A universidade pública, historicamente produtora de conhecimento e difusora desse modelo de ciência, vem passando por dificuldades de legitimação frente às demandas sociais. A saída para esse impasse seria implementar mudanças significativas na relação com diferentes manifestações do conhecimento e suas inter-relações. Tais mudanças seriam necessárias para colocar a universidade como promotora de formas verdadeiramente democráticas de interação (SANTOS, 2005).

Um dos grandes desafios para o desenvolvimento de ações emancipatórias na universidade, que reconheçam diferentes tipos de saber, baseadas numa efetiva participação e num real acesso de todos aos bens públicos e aos bens de produção, é a formação de cidadãos comprometidos com essa causa. Para isso, segundo Santos (2005), a universidade 
deve ter como base o conhecimento pluriversitário através de cinco áreas de ação: 1) acesso; 2) extensão; 3) pesquisa-ação; 4) ecologia de saberes; e 5) universidade em comunhão com a escola pública.

Dessas cinco áreas de ação, as quatro primeiras - principalmente a ecologia de saberes em sua perspectiva intercultural - nos serão particularmente importantes para analisar o processo de formação de estudantes no âmbito do Programa Extensionista TEIA (PROEXT/MEC/ $\mathrm{SESu}$ ). Esse Programa reúne e articula projetos ligados a vários departamentos da Universidade Federal de Viçosa (UFV) e suas bases sociais. Esses projetos possuem em comum: concepções, práticas e metodologias promotoras de relações entre diferentes saberes, agentes, atores e autores (BARBOSA, 2005; BARBOSA, 2006). Buscam a construção de um modelo de desenvolvimento sustentável, efetivo e de densas bases sociais, valorizando o compartilhamento entre os saberes populares e científicos.

Desenvolvido desde 2005, o TEIA busca concretizar ações voltadas para a construção coletiva de saberes, estabelecendo novas interfaces entre atividades de extensão, ensino e pesquisa. Envolve-se no tensionamento e na busca de favorecer encontros interculturais, a partir de temas como a questão ambiental, as alternâncias educativas e solidárias e a construção e a disponibilização de tecnologias sociais para o fortalecimento da agroecologia. Suas atividades buscam negociações e sintonia com as demandas dos grupos e movimentos sociais, voltando-se para os setores mais excluídos da população - agricultores(as) familiares, atingidos(as) por barragens, trabalhadores(as) sem terra, moradores(as) de periferia, estudantes e professores(as) do sistema educacional etc.

Um importante procedimento do Programa é a presença de uma atitude investigativa. A pesquisa da realidade, a capacitação dos envolvidos e a produção do conhecimento são dimensões inseparáveis e interligadas à extensão universitária, orientadas pelos pressupostos teóricometodológicos da dialogicidade e da pesquisa-ação.

Os acadêmicos que fazem parte dos projetos vinculados ao TEIA estão sempre em contato com movimentos sociais populares, em vivências contínuas junto à realidade das comunidades.

A proposta deste artigo é avaliar, orientado pelos princípios de Boaventura (2005), se a experiência de bolsistas do Programa TEIA favorece a formação de sujeitos integrados a uma proposta emancipatória e condizente com os pressupostos de uma ecologia de saberes. Assim, 
foram entrevistados, como se explicitará adiante, cinco acadêmicos distribuídos entre os cursos de Ciências Sociais, Geografia, Gestão de Cooperativas e Pedagogia, que fizeram parte do quadro de bolsistas do Programa no ano de 2010 e que são oriundos das bases sociais de projetos vinculados.

\section{Uma pluriversidade é possível?}

Segundo Santos (2011), o paradigma da modernidade vem passando por uma crise. Ele defende a tese de que esse paradigma é gerador de irracionalidades, refletindo uma crise do processo civilizatório instaurado por sua conjunção com o modelo capitalista. As evidências dessas crises verificam-se na conversão do progresso em acumulação capitalista, na iminência de uma catástrofe ecológica, na consolidação de um pensamento único e na expansão da mercadorização ao limite.

Dessa forma, Santos $(2007,2011)$ acredita que a atual crise de regulação social corre junto à crise de emancipação social, sendo necessária uma alternativa radical a esse modelo. A direção da transformação social, além de um ato científico, é um ato político que articula a análise científica com o pensamento utópico. Santos afirma que, ao final do século XX, a única utopia real seria ecológica e democrática, chamada por ele de socialista. Dessa forma, Marx é colocado como ponto de partida para a análise das contradições do capitalismo, que são a predominância do poder social e político do capital sobre o trabalho e sua tendência para crises de superprodução e destruição de suas próprias condições de produção.

Embora coloque como positiva a análise global da sociedade capitalista por Marx, além da vontade de utopia que ele instaura, Santos (1997) ressalta que a divisão da sociedade em classes é um dos pontos mais problemáticos dessa teoria. Os embates políticos voltados para transformações significativas não foram conduzidos por grupos diretamente classistas ou vinculados a interesses exclusivamente econômicos. Dessa forma, propõe que se abandonem os agentes históricos únicos, evidenciando as múltiplas faces da dominação e da opressão: "para além de uma causalidade econômica, as classes sociais manifestam-se politicamente, vinculadas a práticas sociais concretas" (SANTOS, 1997). Partindo desse pressuposto, Santos $(2007,2011)$ aponta para a necessidade de 
reflexão sobre o papel da cultura e da política para a reinvenção da emancipação social.

Segundo ele, "temos problemas modernos para os quais não temos soluções modernas" (SANTOS, 2007, p.19), seja na ciência, seja nas formas de regulação social. Constrói, assim, uma proposta epistemológica, alinhando teoria e prática social por meio de uma reflexão que se esforce em entender o mundo sob uma perspectiva mais ampla que a compreensão moderna (SANTOS, 2011).

Essa forma de racionalidade deve ser interculturalmente combatida, pois se trata de uma razão "indolente, preguiçosa, que se considera única, exclusiva, e que não se exercita o suficiente para poder ver a riqueza inesgotável do mundo" (SANTOS, 1997, p.25). Suas formas de manifestação mais importantes são a razão metonímica e a razão proléptica. A rą̧ão metonímica é uma racionalidade que tem como característica tomar a parte pelo todo, a partir de um conceito limitado de totalidade construído por partes homogêneas, sendo essa racionalidade responsável pelo desperdício da experiência através da contração, diminuição e subtração do presente. Já a razão proléptica é aquela que se pretende conhecedora, no presente, da história futura, depositando nela um sentido de progresso e de desenvolvimento em relação ao que está posto. A razão proléptica é assim responsável pelo desperdício da experiência presente (SANTOS, 2007).

Para combater essas manifestações da racionalidade indolente, Santos interpreta que a crise epistemológica e social na qual vivemos inverte a relação entre expectativas e experiências. Se, na perspectiva moderna, havia uma restrição da experiência e uma expansão da expectativa, a situação em que nos encontramos demanda uma restrição das expectativas e uma ampliação das experiências presentes - porque, nas razões metonímica e proléptica, as possibilidades presentes e futuras são restritas ao discurso científico (SANTOS, 2007, 2011). Assim, propõe uma sociologia das ausências para combater a razão metonímica e uma sociologia das emergências para combater a razão proléptica.

A sociologia das ausências é um procedimento transgressivo, uma sociologia insurgente para tentar mostrar que o que não existe é produzido ativamente como não existente, como uma alternativa não crível, como uma alternativa descartável, invisível à realidade hegemônica do mundo. E é isso o que produz a contradição do presente, o que diminui a riqueza do presente (SANTOS, 2007, p.28-29). 
Nesse sentido, o papel da sociologia das ausências é justamente credibilizar e fazer ver as experiências sociais marginalizadas e seus conhecimentos subjacentes, tornando-os presentes, transformando a ausência em presença. Para tanto, é necessário substituir as interpretações restritas e monoculturais por uma ecologia de saberes, para que se possa dilatar o presente a partir de múltiplas experiências. A ecologia dos saberes consiste, pois, na delicada e difícil experiência de diálogo intercultural entre os saberes científicos e os saberes por eles historicamente desprezados.

Já a sociologia das emergências é a crítica da razão proléptica e sua tentativa de presumir o futuro. A sociologia das emergências substitui um infinito vazio "por um futuro concreto, de utopias realistas, suficientemente utópicas para desafiar a realidade que existe, mas realistas para não serem descartadas facilmente" (SANTOS, 2007, p.37). Essa tentativa consiste em credibilizar e ampliar as possibilidades que existem no presente e que são portadoras de futuro - experiências que busquem e apontem para um futuro baseado nas experiências ampliadas no presente.

Essas abordagens e ações a elas conectadas serão responsáveis pelo procedimento de tradução, por reconhecer realidades antes ignoradas, sendo necessário "criar uma inteligibilidade recíproca no interior da pluralidade" (SANTOS, 2007, p.39), articulando realidades heterogêneas sem colocá-las em uma teoria geral homogeneizante. Esse procedimento intercultural busca conhecer o que existe de distinto e de semelhante entre as realidades, sua correlação de forças, e assim criar inteligibilidade sem destruir a diversidade e suas diferenças. Tais questões são uma tentativa de renovação da teoria crítica a partir de propostas de enfrentamento da injustiça social e busca da emancipação social.

A universidade tem um importante papel no apoio e desenvolvimento das propostas emancipatórias, devendo participar ativamente na construção da coesão social. Contudo, vem demonstrando uma significativa perda do espaço hegemônico na produção de conhecimento, podendo-se dizer de uma crise institucional. Isso se deve, em grande parte, ao fato de que o conhecimento universitário produzido ao longo do século XX distanciou-se das premências do quotidiano das sociedades. Segundo Santos (2005), para que a universidade pública combata a crise, deve promover alternativas de pesquisa, formação, extensão e organização que respondam positivamente às demandas sociais, baseando-se em um modelo de conhecimento pluriversitário. Esse conhecimento deve-se orientar por 
cinco áreas de ação: 1. Acesso; 2. Extensão; 3. Pesquisa-ação; 4. Ecologia de saberes; e 5 . Universidade em comunhão com a escola pública.

Em relação ao acesso, Santos propõe ações voltadas para a sua democratização, por exemplo, a promoção de parcerias entre a universidade e a escola pública no domínio pedagógico e científico; gratuidade da universidade pública e auxílio em forma de bolsas - e não empréstimos aos estudantes de classes trabalhadoras; enfrentamento das discriminações raciais, étnicas e socioeconômicas, com programas de ação afirmativa para o acesso e acompanhamento dos alunos que as sofrem.

Sobre a extensão, além de argamassa de geração de interdisciplinaridade e privilégio na conexão ensino-pesquisa, afirma a necessidade de atribuir uma nova centralidade às atividades de extensão e concebêlas de modo alternativo aos ditames do capitalismo, em contraposição à crescente mercadorização das atividades de extensão, que têm visado prioritariamente à arrecadação de recursos extraorçamentários, ao que se convencionou denominar terceirização de serviços. Para tanto, é necessário que se atribua "às universidades uma participação ativa na construção da coesão social, no aprofundamento da democracia, na luta contra a exclusão social e a degradação ambiental, na defesa da diversidade cultural" (SANTOS, 2005, p.73), em apoio solidário à resolução de problemas sociais e dando-se voz, nesse processo, aos grupos excluídos e discriminados.

Transcendendo a área tradicionalmente dita como de domínio da extensão, o autor propõe a pesquisa-ação e a ecologia de saberes, que atuam também junto à pesquisa e à formação. Para ele,

A pesquisa-ação consiste na definição e execução participativa de projetos de pesquisa, envolvendo as comunidades e organizações sociais populares a braços com problemas cuja solução pode beneficiar dos resultados da pesquisa. Os interesses sociais são articulados com os interesses científicos dos pesquisadores, e a produção do conhecimento científico ocorre, assim, estreitamente ligada à satisfação de necessidades dos grupos sociais que não têm poder para pôr o conhecimento técnico e especializado ao seu serviço pela via mercantil (SANTOS, 2005, p.75).

Dessa forma, afirma a necessidade de uma nova forma de produção de conhecimento, de uma pesquisa muito mais democrática, que reconheça os conhecimentos descredibilizados pela racionalidade indo- 
lente e parta das reais necessidades e interesses sociais em comunhão com os interesses dos pesquisadores.

Já a ecologia de saberes parte do aprofundamento da pesquisa-ação e consiste na promoção de espaços em que os saberes ditos leigos possam dialogar com os saberes científicos produzidos pela universidade, promovendo uma "nova convivência ativa de saberes no pressuposto que todos eles, incluindo o saber científico, se podem enriquecer nesse diálogo" (SANTOS, 2005, p.77).

Por fim, propõe ações que coloquem a universidade em comunhão com a escola pública, afirmando a necessidade do compromisso da universidade com a produção e difusão de saberes pedagógicos, de pesquisas educacionais e de formação dos docentes da escola pública, visando, de forma ampla, à melhoria da educação básica.

Assim, a universidade estaria cumprindo seu papel, enquanto instituição pública, de formulação de ações que visem à solidariedade, tanto na formação dos estudantes como nas atividades de ensino, pesquisa e extensão, constituindo-se em um espaço de construção de alternativas em busca da emancipação social.

A partir das análises acima, orientadas basicamente pelo referencial de Santos, foram demonstradas possibilidades de ações alternativas e contra-hegemônicas voltadas à emancipação social através do envolvimento de diferentes sujeitos e espaços sociais. Nesse sentido, percebe-se a importância de uma educação intercultural que seja um instrumento de formação na busca pela realização universitária democratizante.

\section{A experiência do Programa TEIA}

A Universidade Federal de Viçosa, apesar de historicamente ter sido colocada a serviço da monocultura e do grande capital, conta com a resistência de trabalhos orientados por princípios que poderiam caracterizá-la como um espaço pluriversitário. Dentre eles, o Programa TEIA foi escolhido como objeto de estudo, em sua busca por consolidar e articular projetos que compartilhem concepções, práticas e metodologias de ensino, pesquisa e extensão universitária, baseadas no eixo teórico-metodológico da educação popular, das alternâncias educativas e da agroecologia. Faz isso por meio de diferentes projetos e parcerias, como o movimento 
agroecológico, o movimento pela educação no campo, a economia solidária, a questão de gênero, entre outros.

Dada a proximidade do Programa aos movimentos do campo, a agroecologia, estreitamente relacionada à educação do campo, torna-se uma de suas principais bandeiras. A agroecologia se baseia na transdisciplinariedade e propõe um desenvolvimento sustentável e holístico do ser humano. Está voltada para a melhoria da qualidade de vida, a segurança e soberania alimentar, a inclusão social, a cooperatividade, a oportunidade de permanência do homem no campo, dentre outros. Em termos de produção agrícola, a agroecologia propõe que haja uma combinação entre a dinâmica natural dos ecossistemas com cultivos agrícolas, procurando alcançar e respeitar a biodiversidade (GUZMÁN; MOLINA, 1996).

Em contraposição ao agronegócio, considerada uma forma excludente e insustentável para a vida no campo, a agroecologia, junto com as outras temáticas relacionadas à educação do campo, é apoiada pelo Programa TEIA junto às Escolas Famílias Agrícolas (EFAs).

A perspectiva político-pedagógica do Programa TEIA está alicerçada nas propostas de educação popular e da metodologia de pesquisa participante de Paulo Freire (1981) e Carlos Rodrigues Brandão (1984, 1987). Por educação popular é compreendida a necessidade do ser humano de expressividade, de comunicação (FREIRE, 1981), frequentemente ignorada pela educação tradicional. A educação popular, assentada principalmente na metodologia de pesquisa participante (FREIRE, 1981; BRANDÃO, 1986; BRANDÃO, 1987), busca desenvolver uma compreensão crítica do mundo através de sua problematização e de uma ação transformadora sobre ele. Segundo Paulo Freire (1968), essa ação exige uma rigorosa capacitação e avaliação dos trabalhos dos educadores de base.

Nas atividades desenvolvidas pelo Programa TEIA, de acordo com as propostas da pesquisa participante, a formação de todos os responsáveis pelo desenvolvimento das atividades ocorre de forma sistemática e conjunta com parceiros no planejamento, na preparação e nas avaliações posteriores.

A “Troca de Saberes" é um evento emblemático do modo de funcionamento do Programa TEIA junto com parceiros. Trata-se de um evento anual com duração de quatro dias, no campus da Universidade Federal de Viçosa, e pode ser considerado como um espaço de avaliação 
e planejamento das atividades desenvolvidas pelos projetos do TEIA junto aos parceiros. Durante esses quatro dias, são realizadas mesas de debates - envolvendo temas relevantes levantados nas ações junto aos parceiros, como agrotóxico, agroecologia, conflitos ambientais etc. - instalações pedagógicas, ${ }^{2}$ atividades culturais, plenárias para avaliação das atividades do dia, dentre outras. O planejamento da Troca de Saberes se inicia cerca de um mês antes do evento, com reuniões abertas à comunidade a partir das quais se organizam comissões (metodologia, cultura, instalações pedagógicas, relatoria e infraestrutura) compostas por professores, bolsistas e parceiros. As decisões tomadas nessas comissões são apresentadas e discutidas nas reuniões gerais e socializadas com parceiros que estão em outras localidades. Nesse período preparatório, ocorrem as simulações das instalações pedagógicas, a formação dos relatores, a preparação da infraestrutura etc. O volume de tarefas a serem realizadas para a viabilização das atividades é significativo, uma vez que envolve, além das atividades em si, o deslocamento, alimentação, acomodação, orientação e distribuição de cerca de 300 participantes nas atividades desenvolvidas. Grande parte dessas atividades é desenvolvida pelos bolsistas a partir das deliberações em cada uma das reuniões.

Cerca de um mês após o término do evento, é realizada uma avaliação festiva com os participantes do processo, identificando aspectos positivos, negativos e prospectivos para as ações a serem desenvolvidas pelo Programa TEIA até o próximo evento. Embora seja um espaço aberto, restringe-se geralmente a um grupo mais envolvido desde o início com o planejamento.

Compreender a forma como o Programa realiza o processo de tradução junto aos parceiros e como isso oferece a seus bolsistas uma formação compatível com essa concepção mostrou-se uma forma de avaliar a pertinência das propostas de Santos (2005), além de possibilitar corrigir distorções e/ou fortalecer as ações do Programa, bem como estimular o avanço reflexivo nos diferentes espaços de formação e de multiplicação do pensamento teórico. 


\section{Metodologia}

O presente artigo analisa os resultados de uma pesquisa qualitativa que possibilita a obtenção de dados descritivos mediante contato direto e interativo do pesquisador com a situação objeto de estudo. Em certa medida, os métodos qualitativos se assemelham a procedimentos de interpretação dos fenômenos que empregamos no nosso dia a dia, que têm a mesma natureza dos dados que o pesquisador qualitativo emprega em sua pesquisa.

Quanto aos objetivos, trata-se de uma pesquisa descritiva (MARCONI; LAKATOS, 1996), uma vez que tem por finalidade avaliar um programa a partir de um referencial teórico. Ou seja, buscaremos compreender se o referencial teórico de Santos (2005) influencia as ações de formação do Programa TEIA a partir dos relatos de seus bolsistas.

Quanto aos procedimentos, a pesquisa pode ser caracterizada como bibliográfica, documental e estudo de caso. A pesquisa bibliográfica, bem como a pesquisa documental se caracterizam por utilizar fontes secundárias e primárias, respectivamente, sobre o Programa TEIA,

[sendo útil] não só por trazer conhecimentos que servem de background ao campo de interesse, como também para evitar possíveis duplicações e/ou esforços desnecessários; pode, ainda, sugerir problemas e hipóteses e orientar para outras fontes de coleta (LAKATOS; MARCONI, 1985, p.165).

A pesquisa documental consistiu na análise do Projeto de Extensão (PROEXT/MEC/SESu) que deu origem e sustentação teóricometodológica ao Programa no ano de 2010. A pesquisa bibliográfica procedeu à análise de trabalhos acadêmicos realizados em sua maioria por participantes e ex-participantes do Programa, como dissertações de mestrado, monografias, trabalhos de conclusão de curso, artigos e resumos de eventos. Buscou-se, nessa etapa, compreender os princípios conceituais e metodológicos da proposta do TEIA e seu histórico. Objetivava-se identificar a similaridade entre o discurso no projeto, discurso dos autores mencionados e discurso dos integrantes.

A releitura do projeto TEIA evidenciou maior afinidade dos discursos apresentados no projeto em relação a Boaventura de Souza Santos, fato que orientou a sua escolha como principal referencial teórico, facilitando, assim, a avaliação do Programa. Para tanto, elegemos suas propo- 
sições acerca de um novo posicionamento da universidade pública, com base em uma ciência pluriversitária, conforme já elucidamos.

Dentre as formas possíveis de se realizar uma pesquisa qualitativa, escolhemos o Estudo de Caso, do qual o Programa TEIA foi nosso objeto, pois, Segundo Gil (2010, p.37), o estudo de caso se caracteriza pelo "estudo aprofundado e exaustivo de um ou poucos objetos, de maneira que permita seu amplo e detalhado conhecimento". Para tanto, utilizamos como instrumento de pesquisa a realização de entrevistas semidirigidas, individuais e coletivas, junto a bolsistas que participam ou participaram dos projetos desenvolvidos pelo Programa. As entrevistas versaram sobre as principais concepções compartilhadas por eles sobre sua participação e formação no TEIA a partir de quatro dos temas propostos por Santos (2005) para a construção da universidade no século XXI.

Dessa forma, para esclarecimentos a respeito do acesso e permanência dos universitários e sua relação com a ação do TEIA, foram entrevistados bolsistas oriundos de projetos vinculados ao Programa: dois do cursinho popular Tecendo Sonhos e dois da EFA Paulo Freire. Para apreendermos aspectos da história e pressupostos teórico-metodológicos do Programa, especialmente em relação aos princípios de extensão, pesquisa-ação e ecologia de saberes, que a hipótese da pesquisa acredita subjazerem às ações do TEIA, foi entrevistada, além dos quatro bolsistas mencionados, uma ex-bolsista com ampla atividade no Programa, tanto em termos de ações realizadas quanto em tempo de atuação. Foram entrevistados, portanto, um total de cinco bolsistas.

\section{Programa TEIA: texto e contexto}

\section{Os quatro pilares do Programa TEIA:}

acesso, permanência, pesquisa-extensão e a ecologia dos saberes

Para Santos (2005), um dos principais passos a ser dado pelas universidades públicas, no século XXI, seria sua universalidade, ou seja, a garantia do acesso da população comum aos conhecimentos universitários, com o devido reconhecimento de seus próprios saberes. Para tanto, o conhecimento produzido pela universidade deveria ser democratizado, tanto no desenvolvimento de parcerias entre a universidade e a escola 
pública, no domínio pedagógico e científico, como no ingresso e permanência de ingressantes de classes trabalhadoras e de grupos que sofrem discriminações raciais, étnicas e socioeconômicas. Programas de ação afirmativa para o acesso e acompanhamento de alunos que se encontram nessa situação garantiriam o diálogo entre esses setores e os saberes acadêmicos dos quais historicamente se mantiveram afastados.

Embora o Programa TEIA não tenha uma ação direta sobre as políticas universitárias de acesso, os projetos desenvolvidos junto a diferentes parceiros ligados ao ensino médio têm por objetivo a formação desses alunos. Dois projetos desenvolvidos pelo Programa TEIA têm essas características, a saber, o cursinho popular Tecendo Sonhos $^{3}$ e a Escola Família Agrícola Paulo Freire. ${ }^{4}$

Para avaliar a relação entre o Programa TEIA e a discussão do acesso universitário, foram entrevistados quatro bolsistas do Programa TEIA, dois deles estudaram no cursinho popular Tecendo Sonhos, e dois estudaram na EFA Paulo Freire. Uma ex-bolsista foi entrevistada para ampliar as discussões do Programa com as demais ações propostas por Boaventura de Sousa Santos: a pesquisa-ação, a extensão universitária e a ecologia de saberes.

As entrevistas sobre o acesso e a permanência no espaço universitário tiveram por objetivo compreender se os bolsistas entrevistados identificavam contribuições do Programa TEIA em sua trajetória anterior à entrada na universidade - em outras palavras, a forma como as atividades desenvolvidas anteriormente lhes permitiram conhecer e integrar-se à universidade - bem como o processo de permanência e formação desses bolsistas na universidade como bolsistas do Programa. Interessava-nos ainda saber se a proposta do Programa era clara e suficiente para que desenvolvessem suas atividades junto aos parceiros, e se as consideravam relevantes e diferenciadas em relação a um modelo tradicionalmente desenvolvido nas universidades.

Iniciamos a análise dessas entrevistas a partir do relato dos bolsistas sobre seu contato prévio com os projetos desenvolvidos pelo TEIA.

Paulo Junior e Leandro são ex-moradores da zona rural do município de Espera Feliz (MG) e relataram que a trajetória de estudantes em sua cidade terminava cedo. 
Em 2003, eu terminei meu ensino médio sem perspectiva nenhuma. E aí eu ia fazer o quê, né? Eu vou trabalhar pra ajudar meus pais, vou cuidar da roça, né. $\mathrm{Na}$ verdade, eu queria parar na $8^{\mathrm{a}}$ série pra ajudar meus pais, porque a nossa situação continuava complicada. [...] Mas meus pais falaram pra eu continuar e pelo menos terminar o ensino médio. Aí eu terminei em 2003 e parei de vez, mas fiquei parado mesmo, porque depois que você para de estudar você não tem incentivo nenhum, nem vontade de pegar um livro para estudar (LEANDRO, 2011).

Como descreve Boaventura de Sousa Santos, o histórico distanciamento da universidade em relação às camadas populares apresenta esse espaço como inacessível, principalmente às populações do campo.

E eu não tinha assim, né, as informações em relação à assistência estudantil que tinha aqui em Viçosa. Então eu ficava me perguntando sempre o seguinte, "como é que eu vou me manter em Viçosa?", que eu não sabia que tinha alojamento, bolsa atividade, que a gente poderia conseguir uma bolsa, se inserir num projeto, conseguir uma bolsa também aqui. E aí eram informações que a gente não tinha acesso [...] (PAULO JÚNIOR, 2011).

Foi através do cursinho pré-vestibular Tecendo Sonhos, iniciado em 2007, em uma parceria entre o Programa TEIA e o Sindicato dos Trabalhadores Rurais de Espera Feliz, que Leandro e Paulo Júnior passaram a vislumbrar novas possibilidades para seus estudos. As atividades ocorriam em um espaço cedido pela comunidade em um final de semana todo mês. Todo o trabalho desenvolvido, nesses encontros, era voluntário: dos professores/monitores - que são professores das redes públicas locais e estudantes da Universidade Federal de Viçosa (alguns com bolsas de extensão) - passando pela preparação das refeições para o encontro realizada geralmente por alguma pessoa da comunidade - até a limpeza do local - pelos próprios estudantes do cursinho. Segundo Leandro,

[...] os encontros servem como uma orientação, com relação ao conteúdo. Os encontros são estruturados em eixos temáticos. Por exemplo, esse encontro vai ser sobre habitação, aí todas as disciplinas tentam "casar" os conteúdos com esse tema. A geografia trabalhava os espaços, a história, a questão das construções. Mais ou menos nesse sentido da interdisciplinaridade. Então a partir desses estudos a gente direcionava nossos estudos em grupo. [...] e as possíveis dúvidas a gente tirava no próximo encontro (LEANDRO, 2011). 
Embora o cursinho propusesse auxiliar no aprendizado de jovens da comunidade interessados em ingressar na universidade, sua grande contribuição, segundo Paulo Júnior, estava relacionada à orientação quanto às suas expectativas, à desnaturalização de conceitos sobre as dificuldades de acesso à universidade pública e às possibilidades de permanência na mesma:

Só que, aí, com o cursinho, no decorrer, os meninos [professores/monitores] sempre traziam essas informações pra gente, trazendo essas discussões de informar mesmo, né?! Trabalhando com a ideia de que aqui na universidade, pra quem é filho de agricultor, que não tem grana pra se manter, pra morar na cidade, coisa assim, né, tinham essas políticas de assistência estudantil que davam pra gente se manter (PAULO JÚNIOR, 2011).

Para Paulo Júnior, tendo terminado o Ensino Médio há menos tempo, a aprovação no vestibular veio após o primeiro ano no cursinho Tecendo Sonhos, ingressando em 2009 no curso de Cooperativismo da UFV. Após dois anos frequentando o cursinho, na segunda tentativa de vestibular, Leandro ingressou no curso de Ciências Sociais da UFV, no ano de 2010.

Leandro afirma ter escolhido esse curso por afinidades e interesses pessoais. Não desconsiderou, em sua escolha, porém, a baixa concorrência por vagas no curso e suas dificuldades advindas de sua formação, como em relação à matemática, por exemplo. Segundo Leandro, ao ingressar na UFV, já sabia "se virar bem" na universidade, pois participara da chamada Semana de Vivência, promovida pelo cursinho, nos anos de 2008 e 2009, em que também conhecera várias pessoas que já estavam na universidade. O mesmo é percebido na fala de Paulo Júnior: "o que fez diferença pra mim mesmo, de querer vir pra cá, foi a [Semana de] Vivência, em 2008, setembro de 2008, a gente veio pra cá e ficou uma semana" (PAULO JÚNIOR, 2011).

Essa Semana de Vivência destaca-se por ser uma ação promovida em parceria com o Programa TEIA, em que estudantes dos projetos de intervenção em Educação, como é o caso do cursinho pré-vestibular de Espera Feliz, passam uma semana nas dependências da UFV, frequentando aulas dos cursos de seu interesse, visitando as instalações e convivendo, em regime de acolhimento solidário, com estudantes da universidade, em sua maioria bolsistas do Programa TEIA e outros projetos de educação popular. 
Mesmo com essa experiência, que possibilitou um maior domínio sobre os conhecimentos necessários à entrada em um ambiente desconhecido como a UFV, as dificuldades de permanência demonstraramse logo de início:

E na chegada eu me perguntei, como que eu vou fazer, né? Sem dinheiro pra pagar nada, pra comprar ticket [para se alimentar no Restaurante Universitário]. Nas primeiras semanas, foi tranquilo comprar ticket, porque tinha um pouquinho de dinheiro que tava guardado, mas morar em alojamento, eu fiquei morando clandestino [...] Eu almoçava, e não tomava café não, porque era um gasto a mais. Eu almoçava e jantava só comprando um ticket (LEANDRO, 2011).

Leandro conseguiu a aprovação de sua permanência em alojamento estudantil e bolsa atividade ${ }^{6}$ somente dois meses após o começo das aulas, orientado por participantes do Programa TEIA e projetos parceiros:

Aí o Willer [coordenador do Programa TEIA] me chamou lá e perguntou pra mim como que eu tava fazendo pra comer. Aí eu contei o jeito que tava, né? Aí ele falou, olha lá a questão da bolsa atividade e vem fazer aqui [as atividades] pra você comer (LEANDRO, 2011).

E quando eu cheguei aqui em Viçosa, em fevereiro de 2009, foi muito tranquilo assim, né, porque, em função da rede que já tinha sido constituída durante a Vivência, a gente já tinha conhecido muitas pessoas. Igual, muita gente quando chega aqui na universidade, que não tem casa, lugar e tal, às vezes, vai pra ficar no Hilton, né, lá no porão do Centro de Vivência [...], e já contatava o Vladi. O Vladi foi o bolsista-calouro do cursinho de Espera Feliz em 2008. Fiquei lá uns dias, aí depois até vim pro Hilton mesmo, até como forma de pressionar a universidade pra liberar a nossa bolsa mais depressa, né? (PAULO JÚNIOR, 2011).

A entrada como bolsista no Programa TEIA, em um segundo momento, ampliou a rede de apoio a esses estudantes, que, ao começarem a participar das reuniões do Programa, receberiam agora um auxílio financeiro, visto como de suma importância pelos próprios estudantes para que conseguissem manter-se na universidade.

Aí eu fui me aproximando do TEIA e, no primeiro ano, eu fiquei como bolsista com o professor Edgar, com o projeto de Educação no Campo. Essa 
bolsa que me manteve aqui e me mantém até hoje. Pelo TEIA, eu recebo uma bolsa e, sinceramente, se não fosse essa bolsa, eu já tinha ido embora. Porque meus pais não têm condição de ficar mandando dinheiro pra mim. Essa é a vantagem de um programa como o TEIA, ele te dá essa possibilidade de se manter dentro da universidade, trabalhar, e, por outro, você tem um tempo pra estudar, né?! Porque você mantém seu emprego estudando. E o TEIA entende esse lado do estudante mesmo (LEANDRO, 2011).

Ao ser perguntado se achava que o TEIA o tinha ajudado, Leandro responde:

Ajudou muito e tem ajudado. Eu acho que, pelo menos na parte inicial, até que a gente aprenda a caminhar aqui dentro, o TEIA ajudou demais. Agora, eu já tenho possibilidade de, talvez, pensar um projeto de iniciação científica, não desvinculado do TEIA, mas eu tenho condições de pensar outros caminhos (LEANDRO, 2011).

Nesses momentos iniciais, para Leandro e Paulo Júnior, o TEIA assume uma dupla função. Por um lado, auxilia no contato do aluno com a universidade, desconstruindo um distanciamento que os impediria de tentar e desenvolvendo sua capacidade para se inserir na universidade. Por outro, apoia o aluno imediatamente após sua entrada na universidade, a partir dos laços constituídos, que reduzem o estranhamento em torno desse espaço e o inserem em um contexto de atividades nas quais o aluno já tem alguma experiência, legitimando, assim, seus saberes. Essa entrada, reconhecendo experiências anteriores, já sinaliza para outra forma de envolvimento com a universidade, condizente com as propostas de Santos acerca dos diálogos entre saberes do senso comum e científico. O conhecimento com o qual o aluno entrará em contato na universidade passará pelo crivo de uma construção prévia que demanda uma discussão com o seu "como fazer", ou deverá atender a demandas que ele ainda não conseguiu suprir em suas práticas cotidianas, no contato com as comunidades com as quais trabalha. A familiaridade e a necessidade do conhecimento são importantes não apenas como apoio para a permanência na universidade, mas também como possibilidades futuras no campo de atuação, dada a experiência adquirida na articulação entre as demandas sociais e a busca de ações fundadas para seu enfrentamento.

Por parte de outra bolsista do TEIA, há, ainda, contribuições de outra natureza: 
[...] a bolsa ajudou bastante. [...] tem essa preocupação, não limitar, quanto mais gente tiver dentro desse círculo, quanto mais gente tiver indo nas comunidades, ajudando, vai meio se ramificando, a "teia" vai aumentando e vai ajudando mais gente, não só aqui na universidade como também nas comunidades, com os projetos e tudo (TAÍS, 2011).

De forma semelhante, deu-se a atuação do Programa TEIA em relação ao acesso e permanência de Taís e Pedro, ${ }^{7}$ atualmente estudantes da UFV e bolsistas do TEIA. Eles são oriundos da Escola Família Agrícola Paulo Freire, que também atua em parceria com o Programa TEIA, na cidade de Acaiaca, zona rural da Zona da Mata Mineira. Ambos tiveram seu primeiro contato com o TEIA durante o Ensino Médio, dada a parceria do TEIA com a EFA no desenvolvimento de atividades conjuntas ou mesmo na atuação de bolsistas vinculados ao TEIA como estagiários/monitores de EFA.

Taís teve um histórico de dificuldades iniciais muito semelhante ao de Leandro, passando por dificuldades de alimentação e clandestinidade por mais de um mês na universidade. Pedro só não teve os mesmos problemas por ter uma tia na cidade, com quem contou nos primeiros momentos. Porém, diferentemente de Leandro, não tiveram contato com o TEIA e seus participantes nos primeiros momentos, gerando um sentimento maior de insegurança, superado após as primeiras participações em reuniões do TEIA:

Eu me tranquilizei muito. Porque, no início, assim, eu senti um lugar muito acolhedor, no início do ano, tava aquela coisa de apresentação pros calouros e tudo, isso, eu me senti muito acolhida, eu ia na reunião, eu me tranquilizava muito [...] Eu me tranquilizei, assim, eu tava meio assustada no início, aí foi me tranquilizando nessas questões [...] (TAÍS, 2011).

Pedro também vivenciou esse acolhimento, além de uma abertura muito grande para o diálogo e para a fala, ajudando-o a se expressar melhor. Caracteriza-se, assim, uma marcante percepção em relação às ações do TEIA, como a extensão, a pesquisa-ação e a ecologia dos saberes na formação dos bolsistas. Essa é uma das características mais marcantes, na percepção dos bolsistas, em relação ao TEIA, apresentando-se de forma muito semelhante nos relatos de Leandro e Kyvia: 
Tinha dificuldade de me expressar. Tỉnha o espaço, mas não me colocava. $\mathrm{E}$ isso eu acho que veio da minha formação também, eu acho. [...] hoje é bem mais tranquilo. Hoje eu converso melhor. Até porque houve um amadurecimento, né? (LEANDRO, 2011).

[...] porque o interessante do TEIA é como que ele empodera a gente também da fala. E eu principalmente tinha muita dificuldade de falar. Então, eu acho que, como eu tinha dificuldade de me expressar, eu acho que também tinha dificuldade de refletir sobre as coisas. Quando eu passei a refletir sobre essa academia, né, o que entra nessa academia, né, quais são as outras pessoas, o que meu departamento tá fazendo, né, o que a universidade faz pela sociedade... isso até hoje, na verdade, eu to diluindo, mas foi a partir do momento que eu comecei a falar sobre isso (KYVIA, 2011).

A formação desses bolsistas para o desenvolvimento de ações extensionistas é, dessa forma, sentida como diferenciada:

Eu acho que o TEIA é diferenciado, sim. Porque tem essa proposta da construção, né, você constrói as coisas junto ali. Geralmente, os outros espaços, é uma coisa meio que imposta, né? Que nem um projeto de pesquisa que você tem que seguir tal linha. Ou projeto de extensão que você vai atender aquela comunidade, e acaba não fazendo um intercâmbio com outros projetos [...] e acaba não fazendo nos outros espaços, se você não correr muito atrás, você acaba não conseguindo fazer esse intercâmbio, essa troca de experiências com outras pessoas e outros projetos, né? (TAÍS, 2011).

[...] que aí as pessoas começaram a perceber, ahh, eu tô aqui, no TEIA, pra um trabalho que é um diferencial, né, dentro da sociedade, dentro da universidade (KYVIA, 2011).

E saindo um pouco pra fora do TEIA, ele é visto como "o" diferente, é uma contracorrente (LEANDRO, 2011).

Em alguns casos, essa forma de se organizar e agir do Programa causa estranhamento por parte dos próprios bolsistas, em um primeiro momento, acostumados a conviver com uma lógica de organização universitária hierarquizada e assistencial:

Senti bastante estranhamento (risos). E até falei com o Persiano na primeira reunião do TEIA que eu participei, com a galera assim, né, essa procura da autogestão e de ter essa liberdade de poder falar, de como é que você tá, que a gente não tá acostumado com isso, né, [...] é bastante flexível, o TEIA assim, que a gente vem de outras estruturas que têm uma hierarquia grande (PAULO JÚNIOR, 2011). 
A dificuldade que eu tive e tenho até hoje é entender o TEIA. Naquela ocasião ainda mais. Qual o papel do TEIA também. (LEANDRO, 2011).

E eu lembro que foi uma pergunta que era muito, certa, assim, que todo mundo que entrava e até eu também, era "o que é o TEIA?" Gente, essa é a pergunta que, nossa, todo mundo ficava encucado! Porque a gente entrava naquela dinâmica, mas as respostas não eram imediatas... já dadas, assim, sabe [...] ao mesmo tempo que era atrativa pra gente, também era complexo, né? (KYVIA, 2011).

Esse processo de formação do TEIA provoca uma reflexão dos bolsistas sobre o contexto social e universitário em que se inserem e acerca de sua apreensão sobre eles. Assim, as críticas passam pela forma tradicional de acesso à universidade:

Achei [o vestibular] meio assim, desconectado, né. Descontextualizado, assim, né. Muita coisa de decorar, conteúdo ali que você não pode, pra trazer pra vida da gente, assim, não sei se contribui muita coisa, não. É mais só receita de bolo mesmo, você pegar o conteúdo lá, marretar aquele trem e na hora da prova jogar lá e pronto (PAULO JÚNIOR, 2011).

Ao se depararem com esse formato, as reflexões sobre o processo de aprendizagem e produção do conhecimento conflitam diretamente com as propostas desenvolvidas no TEIA.

Acho que o TEIA proporcionou muito mais na minha formação acadêmica, não sei se eu peco em dizer isso, assim, do que o próprio curso, porque... em algumas disciplinas assim, inclusive que eu tenho muita afinidade, que é em ciências, geografia, que é a área que eu gosto, assim, tinha hora que [eu pensava], "gente do céu, o que tá acontecendo", sabe?! "Que ciência, que geografia é essa que não pensa no todo?”, sabe?!” (KYVIA, 2011).

A demanda por uma participação ativa e dialogada no processo de conhecer passa a marcar diferenças na relação que o aluno tradicionalmente estabelece com o espaço universitário.

Quem tá dentro do TEIA é muito mais ativo, participa de muito, muitas atividades, assim, extracurriculares, né?! Movimento Estudantil... mesmo os projetos, assim, acaba se inserindo em vários espaços diferentes. Participa de eventos, que nem a Troca de Saberes, o FOPIR, o Terreiro Cultural, são coi- 
sas que quem tá, assim, de casa, pra biblioteca, pra sala de aula, acaba que não tem essas experiências, né? (TAÍS, 2011).

Assim, a forma como o TEIA se organiza para desenvolver suas ações universitárias se aproxima da proposta de Santos (2005), para quem é necessário atribuir às universidades uma "participação ativa na construção da coesão social, no aprofundamento da democracia, na luta contra a exclusão social e a degradação ambiental, na defesa da diversidade cultural” (SANTOS, 2005, p.73). Tais ações, segundo esse autor, deveriam organizar-se de forma solidária à resolução de problemas sociais, dandose vOz, nesse processo, aos grupos excluídos e discriminados.

O resumo da proposta do Programa TEIA organiza a forma como busca orientar-se a partir de todas essas ações.

O Programa TEIA se propõe a gerar interação entre projetos de extensão a partir da utilização de ações integradoras e de intensa participação popular. Com foco na necessária interligação extensão-ensino-pesquisa, procura a investigação-ação e a interdisciplinaridade através de metodologias participativas e densa dialogidade. Assim, fortalecem-se os vínculos entre universidade e sociedade propiciadores de uma ecologia de saberes que se diferencia dos clássicos difusionismo e assistencialismo (PROGRAMA TEIA, 2009).

Essa preocupação com o apoio solidário na resolução de problemas sociais, voltada para a valorização do conhecimento do grupo atendido, mostra-se recorrente na fala dos bolsistas sobre as ações extensionistas do Programa TEIA:

A gente tenta ajudar na promoção do desenvolvimento daquela comunidade, né, as pessoas entenderem a importância da Agroecologia, da homeopatia, e você acaba aprendendo até mais com eles do que você consegue passar (TAÍs, 2011).

Eu acho que o TEIA é um movimento alternativo. Isso já é muito claro, até pela própria configuração mesmo, sabe?! Eu acho que o encontro, a gente tentar fazer diferente, resgatar várias coisas. Igual o pessoal falava "ahh, vocês ficam usando esse pano de chita...", mas o que é o pano de chita?, vem do meio popular, né?! As rendeiras, então a gente ficava tentando resgatar vários elementos da cultura popular, pra trazer pra discussão (KYVIA, 2011). 
A questão mesmo da formação [...] acho que o TEIA proporciona, pelo menos pra mim, do meu ponto de vista, um crescimento assim, né, de entender as diferenças, de lidar com a diversidade (PAULO JÚNIOR, 2011).

Esses trabalhos que são feitos junto com os agricultores e junto com as famílias e tal, eu acho que tem que entender o contexto que eles estão. Eu acho que também falta um pouco disso, de entender a dinâmica das comunidades e das pessoas que estão lá, pra a partir daí começar o trabalho lá (LEANDRO, 2011).

Orientados por uma lógica de ampliação do presente, conforme proposta de Santos $(2007,2011)$, os bolsistas evidenciam a necessária dialogicidade entre os saberes acadêmicos e os saberes oriundos dos grupos populares com os quais trabalham. Esse conflito intercultural, entre a racionalidade indolente predominante na universidade, suas pesquisas e ações extensionistas, e uma racionalidade baseada no conhecimento pluriversitário de valorização aos conhecimentos marginalizados, como ocorre no Programa TEIA, é relatado pelos bolsistas entrevistados:

Então, esse é um desafio também, né, de trabalhar com pessoas também que têm um conhecimento, mas, pra academia, esses conhecimentos não valem, né? (KYVIA, 2011).

E se você pensar o TEIA disputando espaço, comprando a briga com a Semana do Fazendeiro, de fazer a Troca de Saberes, como é que não tem formação política nisso, né?! Onde acontece o movimento maior do Agronegócio, da Universidade, na concepção da Universidade de que é o maior movimento de Extensão que a própria faz, o TEIA buscar o seu espaço ali dentro com os Movimentos Sociais, com a Assessoria [dos Movimentos Sociais], de cada estudante que tá no TEIA se colocar [...] (PAULO JÚNIOR, 2011).

Que, ao mesmo tempo, assim, que eu tava aprendendo a falar com as pessoas, essas pessoas talvez estavam aprendendo a responder, entende?! E isso era muito comum no meio rural também, né, você chegar e as pessoas terem vergonha de falar, ter que empoderar as pessoas também, de fala, eu acho que é um movimento bacana. Que a agroecologia faz, né, também, que o TEIA fazia, você deixar as pessoas falarem, sobre a vida delas, eu acho que isso já é um processo bacana (KYVIA, 2011).

Trata-se de um modo de produção de conhecimento que legitima os conhecimentos descredibilizados pela racionalidade indolente e 
parte das reais necessidades e interesses sociais em comunhão com os interesses dos pesquisadores.

A proposta do TEIA, como foi apresentada anteriormente, enfatiza esse processo de produção de conhecimento dialogado, tendo a pesquisa-ação como referência, como é possível perceber nos relatos de Kyvia e Leandro:

O TEIA tinha uma coisa muito interessante que era a ida a campo, sabe? Eu participei, por exemplo, de alguns diagnósticos junto com o pessoal do PACAB (Projeto de Assessoria às Comunidades Atingidas por Barragens). Então, eram pessoas, agricultores, que iam perder a terra. No contato com aquelas pessoas ali, às vezes, a gente ia fazer uma entrevista, alguém chorava na sua frente, "por que eu tenho que sair da minha terra?", então vinham várias questões, e quando você retorna pra universidade, você vê o que a universidade tá produzindo, de coisas mesmo, pra esses tipos de situação? Que a universidade vem com essa coisa do avanço, mas como ela tá atingindo, né?! Esse tipo de coisa, que, ao mesmo tempo que a gente do TEIA ia a campo, iam vários outros estudantes da própria universidade, fazendo o trabalho contrário, o oposto assim, né?! Você via muitas produções que era bem isso, assim (KYVIA, 2011).

O fato maior é: onde eu vejo isso na prática? Onde que isso toca a realidade? Eu vou aprender a ser um pesquisador de "porteira" pra dentro? Saiu das quatro pilastras ${ }^{8}$ pra lá e aî? E agora? (LEANDRO, 2011).

A promoção de espaços em que os saberes ditos leigos dialogam com os saberes científicos universitários, enriquecendo a ambos, é intitulada "ecologia de saberes" por Boaventura de Sousa Santos, à qual estamos agregando a perspectiva da educação intercultural em seu sentido de desvelamento de poderes intrínsecos às relações.

Segundo tal descrição, a ecologia de saberes parece tratar-se de uma concepção que permeia todas as ações de interlocução e diálogo com os grupos e comunidades com os quais o TEIA atua em parceria. Essa concepção é retratada na fala de Kyvia, ao relatar como objetivo das pessoas que constroem o Programa uma forma de relação diferenciada com o saber popular:

Qual que era o objetivo nosso em comum? É de tratar as pessoas [de forma] diferente, é de tratar de conhecimentos, né, como seria esse conhecimento do agricultor, né, e como seria, como esse conhecimento tá sendo na universidade, como que isso se ressignifica (KYVIA, 2011). 
É possível apreender, através da fala do bolsista Leandro, a concepção de ecologia de saberes que permeia as ações do Programa TEIA e culmina na realização de um projeto como a Troca de Saberes, diferenciando-se de outros programas e projetos de extensão da universidade:

Pelo menos, com os projetos que eu tenho mais contato e vejo, assim. Eu acho que é a questão da valorização do que tem aqui dentro e não de lá pra cá. Entendeu? Valorizam a cultura que tem do lado de dentro das quatro pilastras. E tem muito projeto de extensão que eu vejo, que é no sentido de levar daqui [UFV] pra lá, e não trazer de lá pra cá. E aí tem toda uma forma de estruturação fora da universidade que tem características próprias deles. Igual, você vai pra uma comunidade igual Espera Feliz fazer uma atividade de extensão e pensa que você tem que levar conhecimento para eles, porque eles não sabem nada. Mas será que eles não têm conhecimento nenhum? Não é bem assim, né. Eu acho que o TEIA valoriza muito isso, sabe, essa partilha, que é a chamada "troca de saberes". O TEIA tem muito disso de valorizar o conhecimento local, porque o que vem de lá também tem toda importância. E aí eu acho que isso diferencia muito o TEIA de outros projetos de extensão dentro da UFV (LEANDRO, 2011).

Por fim, é possível notar a interpretação dos bolsistas e ex-bolsistas em relação à própria formação que tiveram ou continuam tendo no âmbito do Programa como positiva e diversa do que percebem em outros âmbitos, e que acreditam ser enriquecedora pela forma de lidar com os diferentes espaços e conhecimentos.

Acho que a ideia do TEIA, no meu entendimento, também é isso, né, trabalhar como modificador, depois que formar levar essa formação que a gente tá tendo também pra outros espaços... (PAULO JÚNIOR, 2011).

E aí eu consigo perceber, assim, a dimensão da formação que o TEIA me proporcionou, igual, eu consigo fazer um diagnóstico rápido participativo, não porque é o curso de pedagogia, e nem o projeto de extensão, mas porque quando eu participei do TEIA eu tive oportunidade de fazer. Então eu fui vendo essa dimensão, a própria escrita, né, a minha escrita (KYVIA, 2011).

A análise das informações, sejam elas documentos do Programa TEIA ou entrevistas, permite verificar que as ações desenvolvidas por esse Programa não apenas se orientam, mas conseguem implementar uma dinâmica de funcionamento coerente com a proposta de Boaventura de Sousa Santos para a Universidade no século XXI. Em outras palavras, 
encontram-se ações voltadas para a viabilização do acesso bem como a permanência universitária, o desenvolvimento de ações de pesquisa e extensão, com a devida formação, que orienta para a realização da ecologia de saberes proposta por Santos, em estreita relação com o que este vem chamando de sociologia das ausências e das emergências. Lembrando não se tratar da proposta deste artigo avaliar as contribuições do Programa TEIA para os parceiros - permanecendo essa proposta para pesquisas futuras - mas são as ações, a percepção e a formação dos bolsistas que aqui interessaram, considerando as contribuições que o Programa propiciou para sua formação profissional e humana. Na perspectiva de Santos, a constituição de novos espaços de interação, que escapem da lógica da regulação social, possibilita a emergência de um novo mapa emancipatório.

Nesse sentido, a partir dos relatos dos entrevistados, é possível reconhecer que o Programa TEIA contribuiu, de maneira significativa, para a formação desses bolsistas. A permeabilidade dos bolsistas a experiências não estruturadas e em constante diálogo com outros saberes evidencia uma orientação voltada para a atenção aos saberes emergentes. Essas orientações podem ser verificadas na fala dos participantes, como demonstrado no decorrer desta análise.

A ruptura com o modelo hierarquizado de relações, seja entre professor e aluno, seja entre o saber universitário que representam e o saber popular com o qual dialogam e compartilham - como foi observado no relato dos bolsistas oriundos desses movimentos sociais - constitui-se em espaços de tradução e autonomia. Os "espaços de fala" mencionados pelos bolsistas efetivam esses espaços de interação em que alunos participam e se expressam com maior facilidade e frequência, uma vez que a legitimidade dos saberes se dá em sua própria expressão, em lugar de sua forma ou origem.

Parte desse processo de autonomia construído na relação do TEIA com os bolsistas ocorreu pela reinserção dos bolsistas nas atividades junto aos grupos dos quais são oriundos. Nessas circunstâncias, o bolsista não se desfaz do saber com o qual adentra na universidade. Ao contrário, esse saber é importante para o próprio Programa e para as atividades que pretende desenvolver. Mas, como orienta Santos, não se torna um saber colonizado, mas traduzido e que viabiliza o diálogo entre ambos. 
É comum que ex-bolsistas do TEIA, a partir das experiências desenvolvidas, organizem outros projetos e programas autônomos, constituindo o Ambiente TEIA. É o caso do SAUÍPE, grupo de permacultura para classes populares. O SAUÍPE, como outros projetos originados no TEIA, autonomizam-se, mas mantêm laços de interdependência, reforçando-se mutuamente nas pautas que frequentemente compartilham, como agroecologia, economia solidária, gênero, saúde integral, cultura, educação do campo e soberania alimentar.

Se, a partir do que foi relatado, pode-se concluir que as ações do Programa TEIA, na percepção de seus bolsistas e na sua formação, conseguem implementar parte significativa da proposta de Santos para a universidade pública, o mesmo pode ser dito quanto às contribuições esperadas por essas ações para a transformação do espaço universitário, garantindo a indissociabilidade entre ensino-pesquisa-extensão e recuperando a legitimidade das ações universitárias diante das demandas da sociedade civil. Ações estas voltadas para o desenvolvimento de ações emancipatórias.

\section{Conclusão}

Segundo Santos (2005), a relação entre universidade e sociedade tem revelado uma importante transformação, demonstrando uma perda do espaço hegemônico de produção de conhecimento por parte da universidade pública estatal. Nesse sentido, pode-se dizer que existe uma crise institucional.

Para esse autor, a universidade pública deve combater a crise através de uma reforma criativa, democrática e emancipatória, buscando a recuperação da legitimidade da instituição perante a sociedade. Para tanto, deve promover alternativas de pesquisa, formação, extensão e organização que respondam positivamente às demandas sociais, baseando-se em um modelo de conhecimento pluriversitário e comprometido com um projeto de país.

$\mathrm{Na}$ Universidade Federal de Viçosa, alguns programas vêm atuando de forma comprometida com tal filosofia, como é o caso do Programa Extensionista TEIA. O presente artigo buscou analisar algumas contribuições do TEIA no processo de formação de seus bolsistas, iden- 
tificando, em suas falas, correspondências entre as propostas de Santos e suas práticas.

A partir da pesquisa documental do projeto que dá base às ações do TEIA e trabalhos acadêmicos sobre ele, foi possível verificar que o Programa visa a integrar conhecimentos teórico-metodológicos em diferentes áreas do saber com o saber popular, valorizando a cultura e as manifestações artísticas. O principal meio de realização desses objetivos se dá por ação dos bolsistas, o que demanda um processo de formação específico que vem sendo chamado de "formação em ação".

A análise das entrevistas realizadas com bolsistas e ex-bolsistas do Programa TEIA permitiu identificar ações desenvolvidas por esse Programa junto às comunidades, que auxiliaram na sua entrada na universidade. Ações importantes também são realizadas para a permanência dos alunos, seja com auxílio financeiro direto por meio de bolsas de extensão, seja no acompanhamento e acolhimento após ingresso na universidade.

O TEIA é percebido por seus bolsistas como contra-hegemônico em relação ao modelo de ação extensionista vivenciado na UFV. Essa diferenciação é notada pela metodologia dialógica e participativa com que o TEIA busca interagir com os grupos e comunidades atendidos por seus projetos, bem como pelo objetivo compartilhado de encontrar saídas para os problemas sociais de tais grupos através de alternativas sustentáveis e respeitosas à sua cultura. O TEIA trabalha com a lógica da interdependência, construindo relações de parceria, mas favorecendo uma autonomia crescente entre seus participantes.

Em relação à pesquisa-ação e ecologia de saberes, os bolsistas relatam que, embora o TEIA seja um programa primordialmente extensionista, a produção de conhecimento ocorre na valorização dos conhecimentos dos parceiros - conhecimentos marginalizados pela racionalidade moderna - em interação com os saberes científicos.

Dessa forma, tendo em mente as quatro áreas de ação propostas por Santos para a renovação da universidade, conclui-se que o Programa TEIA vem formando seus bolsistas para contribuírem para uma reforma democrática da universidade e das relações de desigualdade inerentes a ela, sendo essa formação percebida pelos próprios bolsistas como diferencial, importante e transformadora, levando-os a agir e refletir criticamente frente aos problemas sociais com os quais são defrontados. 


\section{NOTAS}

1 Por saberes interculturais, Barbosa (2005, p.20) compreende "os processos contraditórios que orientam os modos de ser das populações tradicionais em sua secular luta de resistência aos colonialismos".

2 Segundo Alves et al. (2011, p.11), uma instalação pedagógica "guarda semelhanças com uma instalação artística em sua dimensão estética, na multiplicidade de 'suportes' utilizados e na espacialização que monta e desmonta conforme o contexto em que se insere [...] promove um despertar de sensibilidades a serem re-simbolizadas e interdisciplinarizadas a partir da interpretação dialogada de "leigos"'.

3 O cursinho popular Tecendo Sonhos é desenvolvido pelo Sindicato dos Trabalhadores Rurais de Espera Feliz (MG) desde 2008, em parceria com o Programa TEIA e o Centro de Tecnologias Alternativas da Zona da Mata. Trata-se de um cursinho pré-vestibular em alternância que visa a facilitar o acesso de jovens do meio rural à universidade pública. A formação proposta, no entanto, afasta-se do modelo tradicionalmente conhecido de cursinho pré-vestibular, ao trabalhar conteúdos referentes ao vestibular a partir de elementos do contexto no qual os alunos estão inseridos. Disponível em:

http://www.ufv.br/teia/tecendosonhos.html, Acesso em: 01 jun. 2012.

4 O trabalho do Programa TEIA junto à Escola Família Agrícola Paulo Freire visa a apoiar suas atividades na formação técnica de filhos(as) de pequenos(as) agricultores(as) familiares em agropecuária integrada ao Ensino Médio, com ênfase em agroecologia. As oficinas ecopedagógicas e interculturais do projeto Filosofia na EFA Paulo Freire discutiam temas relativos à agroecologia, vida no campo, Carta da Terra, profissionalização e interculturalidade. Essas ações possibilitavam uma rica interlocução entre as demandas dos movimentos sociais e a Escola (CAON et al., 2008).

5 Os entrevistados optaram por não alterar seus nomes.

6 Programa de assistência estudantil da UFV em que o aluno trabalhava 10 horas por semana para receber o ticket de alimentação. Em 2012, essa modalidade de bolsa foi extinta.

7 Pedro foi o único entrevistado que solicitou que seu nome fosse alterado.

8 As quatro pilastras ficam na entrada da UFV e representam a "separação" entre universidade e cidade. 


\section{REFERÊNCIAS}

ALVES, L. C. F.; BARBOSA, W. A.; CARDOSO, I. M.; MANCIO, A. B.; JUCKSCH, I.; COELHO, E. P.; SANTOS, M. L. (Orgs.). Troca de saberes: flores das sombras da agroecologia. Viçosa, PEC/UFV, 2011.

BARBOSA, W. A. Cultura Puri e educação popular no município de Araponga, Minas Gerais: duzentos anos de solidão em defesa da vida e do meio ambiente. 165f. 2005. Tese (Doutorado em Educação) - Programa de Pós-Graduação em Educação, Universidade Federal de Santa Catarina, Florianópolis, 2005.

BARBOSA, W. A. Engrenados e extensão. In: AMODEO; ALIMONDA (Orgs.). Ruralidades. Viçosa, UFV, 2006. p.201-214.

BRANDÃO, C. R. Pesquisa participante. São Paulo: Brasiliense, 1981.

BRANDÃO, C. R. Repensando a pesquisa participante. 3ed. São Paulo: Brasiliense, 1987.

CAON, P. G.; BARBOSA, W. A.; CAON, K. G.; SILVA, K.; GOMES, C. R. Jovens técnicos da Escola Família Agrícola Paulo Freire: movimentos sociais e educação continuada como uma rede social. Revista de Educação Popular, Uberlândia, v.7, p.127-140, jan./dez. 2008.

FREIRE, P. Ação cultural para a liberdade. 5ed. Rio de Janeiro: Paz \& Terra, 1981.

GIL, A. C. Como elaborar projetos de pesquisa. São Paulo: Atlas, 2007.

GUTIÉRREZ, F.; PRADO, C. Ecopedagogia e cidadania planetária. São Paulo: Instituto Paulo Freire/Cortez Editora, 2000. (Guia da Escola Cidadã, v.3).

GUZMÁN, E. S.; MOLINA, M. G. Sobre la agroecología: algunas reflexiones en torno a la agricultura familiar en España. In: GARCÍA DE LEÓN, M. A. (Ed.). El campo y la ciudad. Madrid: MAPA, 1996. p.153-197. (Serie Estudios).

KYVIA: depoimento [2011]. Entrevistadores: SANTOS, M. L.; KÖLLN, M. Viçosa, UFV, 2011. 1 hora e 12 minutos, entrevista digitalizada. Entrevista concedida à bolsista e orientador da pesquisa de Iniciação Científica PROBIC/FAPEMIG.

LEANDRO: depoimento [2011]. Entrevistadores: SANTOS, M. L.; KÖLLN, M. Viçosa, UFV, 2011. 1 hora e 43 minutos, entrevista digitalizada. Entrevista concedida à bolsista e orientador da pesquisa de Iniciação Científica PROBIC/FAPEMIG.

MARCONI, M. de A.; LAKATOS, E. M. Técnicas de pesquisa. In: Técnicas de pesquisa. São Paulo: Atlas, 1996.

MARCONI, M. de A.; LAKATOS, E. M. Fundamentos de metodologia científica. São Paulo: Atlas, 1985.

PAULO JÚNIOR: depoimento [2011]. Entrevistadores: SANTOS, M. L.; KÖLLN, M. Viçosa, UFV, 2011. 1 hora e 51 minutos, entrevista digitalizada. Entrevista concedida à bolsista e orientador da pesquisa de Iniciação Científica PROBIC/FAPEMIG.

SANTOS, B. de S. Pela mão de Alice: o social e o político na pós-modernidade. São Paulo: Cortez, 1997.

SANTOS, B. de S. A universidade do século XXI. São Paulo: Cortez, 2005.

SANTOS, B. de S. Renovar a teoria crítica e reinventar a emancipação social. São Paulo: Boitempo, 2007.

SANTOS, B. de S. A crítica da razão indolente: contra o desperdício da experiência. 8ed. São Paulo: Cortez, 2011.

TAÍS: depoimento [2011]. Entrevistadores: SANTOS, M. L.; KÖLLN, M. Viçosa, UFV, 
2011. 1 hora e 2 minutos, entrevista digitalizada. Entrevista concedida à bolsista e orientador da pesquisa de Iniciação Científica PROBIC/FAPEMIG.

Recebido em: 05/03/2013

Aprovado em: 12/08/2013

Contato:

Programa de Pós-Graduação em Educação Universidade Federal de Viçosa

Campus Universitário

Avenida Peter Henry Rolfs, s/n

CEP 36571-000

Viçosa |MG | Brasil 